Article

\title{
Synergistic Killing and Re-Sensitization of Pseudomonas aeruginosa to Antibiotics by Phage-Antibiotic Combination Treatment
}

\author{
Emily Engeman 1,2 ${ }^{1}$, Helen R. Freyberger 1,3, Brendan W. Corey ${ }^{4}$, Amanda M. Ward 1,3, Yunxiu He 1,3, \\ Mikeljon P. Nikolich ${ }^{1}\left(\mathbb{D}\right.$, Andrey A. Filippov ${ }^{1,3, *(\mathbb{D})}$, Stuart D. Tyner ${ }^{1}$ and Anna C. Jacobs ${ }^{1,3}$
}

1 Center for Infectious Diseases Research, Wound Infections Department, Bacterial Diseases Branch, Walter Reed Army Institute of Research, Silver Spring, MD 20910, USA; emilytengeman@gmail.com (E.E.); hrfreyberger@gmail.com (H.R.F.); amanda_ward45@yahoo.com (A.M.W.); yunxiu.he.ctr@mail.mil (Y.H.); mikeljon.p.nikolich.civ@mail.mil (M.P.N.); stuart.d.tyner.mil@mail.mil (S.D.T.); jacobs.anna.c@gmail.com (A.C.J.)

2 Oak Ridge Institute for Science and Education (ORISE), Oak Ridge, TN 37831, USA

3 ICON plc, Ellicott City, MD 21043, USA

4 Multidrug-Resistant Organism Repository and Surveillance Network, Bacterial Diseases Branch, Center for Infectious Diseases Research, Walter Reed Army Institute of Research, Silver Spring, MD 20910, USA; brendan.w.corey.ctr@mail.mil

* Correspondence: andrey.a.filippov.ctr@mail.mil

\section{check for} updates

Citation: Engeman, E.; Freyberger, H.R.; Corey, B.W.; Ward, A.M.; He, Y.; Nikolich, M.P.; Filippov, A.A.; Tyner, S.D.; Jacobs, A.C. Synergistic Killing and Re-Sensitization of Pseudomonas aeruginosa to Antibiotics by Phage-Antibiotic Combination Treatment. Pharmaceuticals 2021, 14, 184. https://doi.org/10.3390/ ph14030184

Academic Editor: Stephen T. Abedon

Received: 23 January 2021

Accepted: 22 February 2021

Published: 25 February 2021

Publisher's Note: MDPI stays neutral with regard to jurisdictional claims in published maps and institutional affiliations.

Copyright: (c) 2021 by the authors. Licensee MDPI, Basel, Switzerland. This article is an open access article distributed under the terms and conditions of the Creative Commons Attribution (CC BY) license (https:/ / creativecommons.org/licenses/by/ $4.0 /)$.
Abstract: Multidrug-resistant (MDR) Pseudomonas aeruginosa infections pose a serious health threat. Bacteriophage-antibiotic combination therapy is a promising candidate for combating these infections. A 5-phage P. aeruginosa cocktail, PAM2H, was tested in combination with antibiotics (ceftazidime, ciprofloxacin, gentamicin, meropenem) to determine if PAM2H enhances antibiotic activity. Combination treatment in vitro resulted in a significant increase in susceptibility of MDR strains to antibiotics. Treatment with ceftazidime (CAZ), meropenem, gentamicin, or ciprofloxacin in the presence of the phage increased the number of $P$. aeruginosa strains susceptible to these antibiotics by $63 \%, 56 \%, 31 \%$, and $81 \%$, respectively. Additionally, in a mouse dorsal wound model, seven of eight mice treated with a combination of CAZ and PAM2H for three days had no detectable bacteria remaining in their wounds on day 4 , while all mice treated with CAZ or PAM2H alone had $\sim 10^{7}$ colony forming units (CFU) remaining in their wounds. P. aeruginosa recovered from mouse wounds post-treatment showed decreased virulence in a wax worm model, and DNA sequencing indicated that the combination treatment prevented mutations in genes encoding known phage receptors. Treatment with PAM2H in combination with antibiotics resulted in the re-sensitization of P. aeruginosa to antibiotics in vitro and a synergistic reduction in bacterial burden in vivo.

Keywords: Pseudomonas aeruginosa; phage therapy; phage-antibiotic synergy; antimicrobial resistance; re-sensitization

\section{Introduction}

The discovery of penicillin as an antimicrobial in 1928 by Alexander Fleming launched the world into a new era of treating infectious diseases [1]. The antibiotic "golden era" was hallmarked by the development of multiple classes of antibiotics that were effective for decades in controlling infections and reducing morbidity [2]. However, as widespread use of antibiotics increased globally, bacterial pathogens accumulated mechanisms to evade antimicrobial treatments. The emergence of multidrug-resistant (MDR) bacteria coupled with the waning of the antibiotic development pipeline has moved society back into an era where bacterial infections pose a serious threat to human health [3,4].

In 2004, the Infectious Diseases Society of America (IDSA) published the list of ESKAPE pathogens (Enterococcus faecium, Staphylococcus aureus, Klebsiella pneumoniae, Acinetobacter baumannii, Pseudomonas aeruginosa, and Enterobacter species) that have become 
increasingly resistant to antibiotics and cause the bulk of nosocomial infections in hospital settings [5,6]. As a result, the ESKAPE pathogens have become a top target for novel antimicrobial therapies. Among these species is P. aeruginosa, a gram-negative, opportunistic bacterium that can cause complex recurrent infections, particularly in immunocompromised groups [7].

$P$. aeruginosa has acquired multiple mechanisms to evade treatment by current antibiotics including biofilm formation, point mutations, downregulation or loss of outer membrane porins, upregulation of drug efflux pumps, and acquisition of $\beta$-lactamases [6,8,9]. In 2018, the World Health Organization released a priority list of pathogens to target for the discovery of novel antimicrobial solutions, and carbapenem-resistant $P$. aeruginosa was listed as a critical priority in the top tier [10]. Treating an infection caused by MDR $P$. aeruginosa comes at a high cost, with both a significantly higher risk of morbidity and a treatment cost estimated between $\$ 25,300-\$ 32,680$ more for resistant infections compared to susceptible infections [7]. With a scarcity of antibiotics to combat MDR P. aeruginosa, alternative therapeutics are being investigated on their own and as antibiotic adjuvants [11].

A potential alternative therapeutic for treating $P$. aeruginosa infections is lytic bacteriophages (phages). Phages are viruses that specifically bind to, infect, and lyse bacteria. First discovered by Frederick Twort in 1915 and Felix D'Herelle in 1917, the clinical potential of phages was quickly recognized, and phages were successfully used in the treatment of both animal and human bacterial infections in the early 1920s [12]. After the invention of antibiotics, phage therapy lost popularity in the West, but with the rising rates of antibiotic resistance, there has been a renewed interest in the field [13]. Phage therapy is extremely specific, allowing for the selection of phages that kill only pathogenic bacteria and do not target normal microflora. Several studies both in vitro and in vivo have shown the efficacy of various phages in killing P. aeruginosa [14]. Hall et al., investigated the use of a phage cocktail against $P$. aeruginosa and found a significant reduction in bacterial densities in vitro and in wax moth larvae [15]. Phage treatment of $P$. aeruginosa-infected mice showed increased survival and decreased bacterial burden [16-19].

While phage therapy on its own can target and kill bacteria, regulatory hurdles and safety questions have slowed its progress towards clinical trials [20]. As antibiotics are the current standard of care, using phages as an adjuvant to antibiotics instead of on their own may be a more relevant way to apply phage therapy in treating MDR infections [21]. In vitro and mouse model studies have elucidated several phage antibiotic combinations, capable of reducing the bacterial burden more than the additive effects of either treatment alone, termed phage-antibiotic synergy [22,23]. Additionally, the use of phages in combination with antibiotics has been shown to re-sensitize resistant bacteria to antibiotics [24,25].

While not yet approved by the U.S. Food and Drug Administration (FDA), phages in combination with antibiotics have been used in various emergency clinical cases to treat infections caused by MDR P. aeruginosa. Using a phage that binds to a protein of a drug-efflux pump in combination with ceftazidime showed efficacy against $P$. aeruginosa infection both in mice and in a human case of endocarditis [25,26]. Additionally, a recurrent urinary tract infection treated with a phage cocktail in combination with meropenem and colistin resulted in complete infection clearance with no bacteria detected at one year post-treatment [27]. With treatment options becoming increasingly limited due to antibiotic resistance, phage antibiotic combinations need to be further explored for their potential to curb the threat posed by MDR P. aeruginosa infections. The purpose of this study was to investigate the potential synergy of a 5-phage cocktail, PAM2H, in combination with antibiotics (ceftazidime, ciprofloxacin, gentamicin, meropenem) against MDR clinical isolates of $P$. aeruginosa.

\section{Results \& Discussion}

\subsection{Phage Cocktail PAM2H Re-Sensitizes MDR P. aeruginosa Strains to Antibiotics}

In order to determine the level of susceptibility to antibiotics, phages or combination treatment, minimum inhibitory concentrations (MICs) and fractional inhibitory concen- 
trations (FICs) were measured for PAO1, PAO1::lux and 14 phylogenetically diverse MDR $P$. aeruginosa clinical strains. The MIC was determined to be the lowest concentration of antibiotic or phage where there was no visible bacterial growth (Table 1). All of the $P$. aeruginosa diversity set strains and PAO1::lux were classified as resistant to at least two of the tested antibiotics according to Clinical and Laboratory Standards Institute (CLSI) resistance breakpoints (Table 2) [28]. The difference in resistant profiles between PAO1 and PAO1::lux is due to the inclusion of a gentamicin marker on the lux cassette inserted in the PAO1::lux chromosome. The initial experiments were completed using PAO1 because this strain is widely characterized, allowing for comparison of our results to a vast array of previously published data. However, follow-on studies were completed using genetically diverse MDR clinical strains to assess whether our PAM2H phage cocktail has synergistic activity with antibiotics to which the bacterial target strain is resistant.

Table 1. Minimum inhibitory concentration results for antibiotics and phages in different P. aeruginosa strains.

\begin{tabular}{|c|c|c|c|c|c|c|}
\hline \multirow[t]{2}{*}{ Isolate No. } & \multirow[t]{2}{*}{ Source } & \multicolumn{4}{|c|}{$\operatorname{MIC}(\mu \mathrm{g} / \mathrm{mL})$} & \multirow{2}{*}{$\begin{array}{c}\begin{array}{c}\mathrm{MIC} \\
\text { (PFU/mL) }\end{array} \\
\text { PAM2H }\end{array}$} \\
\hline & & CAZ & MEM & GEN & CIP & \\
\hline MRSN321 & Wound & 32 & 16 & 2 & 0.025 & $1 \times 10^{0}$ \\
\hline MRSN994 & Respiratory & 32 & 32 & 4 & 4 & $1 \times 10^{6}$ \\
\hline MRSN2108 & Tissue & 16 & 64 & 2 & 8 & $>1 \times 10^{9}$ \\
\hline MRSN5498 & Tissue & 16 & 32 & 256 & 8 & $1 \times 10^{8}$ \\
\hline MRSN5508 & Fluid & 16 & 32 & 128 & 8 & $1 \times 10^{8}$ \\
\hline MRSN5519 & Wound & 32 & 32 & 128 & 32 & $1 \times 10^{6}$ \\
\hline MRSN6695 & Urine & 128 & 32 & 8 & 2 & $>1 \times 10^{9}$ \\
\hline MRSN8915 & Urine & 4 & 32 & 16 & 64 & $1 \times 10^{4}$ \\
\hline MRSN11538 & Wound & 8 & 32 & 128 & 4 & $1 \times 10^{9}$ \\
\hline MRSN12282 & Respiratory & 32 & 64 & 128 & 64 & $1 \times 10^{2}$ \\
\hline MRSN15678 & Wound & 16 & 16 & 128 & 32 & $1 \times 10^{6}$ \\
\hline MRSN16345 & Urine & 16 & 8 & 1 & 32 & $1 \times 10^{0}$ \\
\hline MRSN23861 & Respiratory & 16 & 256 & 2 & 32 & $1 \times 10^{7}$ \\
\hline MRSN409937 & Fluid & 128 & 16 & 2 & 8 & $1 \times 10^{0}$ \\
\hline PAO1::lux* & Laboratory & 2 & 1 & 32 & 1 & $1 \times 10^{0}$ \\
\hline PAO1 & Laboratory & 1 & 2 & 1 & 1 & $1 \times 10^{0}$ \\
\hline
\end{tabular}

* PAO1::lux has a different resistance profile from PAO1 due to the inclusion of a gentamicin resistance marker on the inserted lux (luciferase) gene cassette.

Table 2. CLSI MIC breakpoints for classifying antibiotic resistance in P. aeruginosa strains.

\begin{tabular}{cccc}
\hline Antibiotic & \multicolumn{3}{c}{ CLSI MIC Breakpoints $\mu \mathrm{g} / \mathbf{m L}$} \\
\hline & Susceptible & Intermediate & Resistant \\
\hline Ceftazidime (CAZ) & $\leq 8$ & 16 & $\geq 32$ \\
Ciprofloxacin (CIP) & $\leq 0.5$ & 1 & $\geq 2$ \\
Gentamicin (GEN) & $\leq 4$ & 8 & $\geq 16$ \\
Meropenem (MEM) & $\leq 2$ & 4 & $\geq 8$ \\
\hline
\end{tabular}

FIC assays were used to determine the susceptibility of the MDR strains to antibiotics in the presence of PAM2H. Each of the 16 P. aeruginosa strains was tested with decreasing concentrations of the PAM2H phage cocktail and antibiotic to determine the lowest concentration of antibiotics that could inhibit growth in the presence of PAM2H (Table 3). The concentration of CAZ in the presence of PAM2H that completely inhibited growth $\left(\mathrm{MIC}_{\mathrm{AB} \Phi}\right)$ was 256-fold lower than the MIC of CAZ alone for 12 of 16 strains. Similarly, for MEM, GEN and CIP, the MIC $\mathrm{AB \Phi}$ was at least 64-fold lower than the MIC for 9, 12, and 12 strains, respectively. Importantly, the presence of PAM2H not only reduced the antibiotic MIC but also rendered the strains susceptible to these antibiotics based on CLSI guidelines 
(Table 2). In the presence of the PAM2H cocktail, the number of strains susceptible to CAZ increased by $63 \%$ and the number of strains susceptible to MEM, GEN, and CIP increased by $56 \%, 31 \%$, and $81 \%$, respectively. These data suggest that including PAM $2 \mathrm{H}$ in combination treatment with an antibiotic that the bacterial target is resistant to could result in efficacious outcomes by re-sensitizing the bacterial strain to the antibiotic.

Table 3. Fractional inhibitory concentrations of antibiotics CAZ, MEM, GEN, and CIP in the presence of the PAM2H phage cocktail.

\begin{tabular}{|c|c|c|c|c|c|c|c|c|c|c|c|c|}
\hline \multirow[t]{2}{*}{$\begin{array}{c}\text { Isolate } \\
\text { No. }\end{array}$} & \multicolumn{3}{|c|}{ Ceftazidime (CAZ) } & \multicolumn{3}{|c|}{ Meropenem (MEM) } & \multicolumn{3}{|c|}{ Gentamicin (GEN) } & \multicolumn{3}{|c|}{ Ciprofloxacin (CIP) } \\
\hline & $\underset{(\mu \mathrm{g} / \mathrm{mL})}{\operatorname{MIC}}$ & $\begin{array}{l}\text { MIC in } \\
\text { the } \\
\text { Presence } \\
\text { of } \\
\text { PAM2H } \\
(\mu \mathrm{g} / \mathrm{mL})\end{array}$ & $\begin{array}{l}\begin{array}{l}\text { Amount } \\
\text { of } \\
\text { PAM2H } \\
\text { (PFU/mL) }\end{array} \\
\text { PFU }\end{array}$ & $\underset{(\mu \mathrm{g} / \mathrm{mL})}{\mathrm{MIC}}$ & $\begin{array}{c}\text { MIC in } \\
\text { the } \\
\text { Presence } \\
\text { of } \\
\text { PAM2H } \\
(\mu \mathrm{g} / \mathrm{mL})\end{array}$ & $\begin{array}{l}\begin{array}{l}\text { Amount } \\
\text { of } \\
\text { PAM2H } \\
\text { (PFU/mL) }\end{array}\end{array}$ & $\underset{(\mu \mathrm{g} / \mathrm{mL})}{\mathrm{MIC}}$ & $\begin{array}{l}\text { MIC in } \\
\text { the } \\
\text { Presence } \\
\text { of } \\
\text { PAM2H } \\
(\mu \mathrm{g} / \mathrm{mL})\end{array}$ & $\begin{array}{l}\begin{array}{l}\text { Amount } \\
\text { of } \\
\text { PAM2H } \\
\text { (PFU/mL) }\end{array} \\
\text { PFU }\end{array}$ & $\underset{(\mu \mathrm{g} / \mathrm{mL})}{\mathrm{MIC}}$ & $\begin{array}{l}\text { MIC in } \\
\text { Presence of } \\
\text { PAM2H } \\
(\mu \mathrm{g} / \mathrm{mL})\end{array}$ & $\begin{array}{l}\text { Amount } \\
\text { of } \\
\text { PAM2H } \\
\text { (PFU/mL) }\end{array}$ \\
\hline PA321 & 32 & 0.0625 & $1 \times 10^{0}$ & 16 & 0.0625 & $1 \times 10^{1}$ & 2 & 0.007813 & $1 \times 10^{1}$ & 0.25 & 0.000976563 & $1 \times 10^{0}$ \\
\hline PA994 & 32 & 0.125 & $1 \times 10^{7}$ & 32 & 0.125 & $1 \times 10^{7}$ & 4 & 0.015625 & $1 \times 10^{7}$ & 4 & 0.015625 & $1 \times 10^{7}$ \\
\hline PA2108 & 16 & 0.0625 & $1 \times 10^{4}$ & 64 & 0.25 & $1 \times 10^{3}$ & 2 & 0.007813 & $1 \times 10^{3}$ & 8 & 0.03125 & $1 \times 10^{3}$ \\
\hline PA5498 & 16 & 2 & $1 \times 10^{5}$ & 32 & 0.25 & $1 \times 10^{7}$ & 256 & 0.5 & $1 \times 10^{7}$ & 8 & 0.03125 & $1 \times 10^{7}$ \\
\hline PA5508 & 16 & 0.0625 & $1 \times 10^{5}$ & 32 & 0.125 & $1 \times 10^{2}$ & 128 & 0.5 & $1 \times 10^{2}$ & 8 & 0.03125 & $1 \times 10^{6}$ \\
\hline PA5519 & 32 & 0.125 & $1 \times 10^{5}$ & 32 & 0.125 & $1 \times 10^{6}$ & 128 & 0.5 & $1 \times 10^{6}$ & 32 & 0.125 & $1 \times 10^{5}$ \\
\hline PA6695 & 128 & 128 & $1 \times 10^{2}$ & 32 & 32 & $1 \times 10^{2}$ & 8 & 8 & $1 \times 10^{2}$ & 2 & 1 & $1 \times 10^{2}$ \\
\hline PA8915 & 4 & 0.015625 & $1 \times 10^{0}$ & 32 & 16 & $1 \times 10^{0}$ & 16 & 16 & $1 \times 10^{0}$ & 64 & 0.25 & $1 \times 10^{0}$ \\
\hline PA11538 & 8 & 8 & $1 \times 10^{7}$ & 32 & 16 & $1 \times 10^{2}$ & 128 & 16 & $1 \times 10^{3}$ & 4 & 0.25 & $1 \times 10^{7}$ \\
\hline PA12282 & 32 & 0.125 & $1 \times 10^{1}$ & 64 & 16 & $1 \times 10^{0}$ & 128 & 2 & $1 \times 10^{0}$ & 64 & 0.25 & $1 \times 10^{0}$ \\
\hline PA15678 & 16 & 0.0625 & $1 \times 10^{5}$ & 16 & 2 & $1 \times 10^{4}$ & 128 & 8 & $1 \times 10^{5}$ & 32 & 0.125 & $1 \times 10^{5}$ \\
\hline PA16345 & 16 & 0.0625 & $1 \times 10^{0}$ & 8 & 0.125 & $1 \times 10^{1}$ & 1 & 0.003906 & $1 \times 10^{0}$ & 32 & 0.125 & $1 \times 10^{0}$ \\
\hline PA23861 & 16 & 16 & $1 \times 10^{3}$ & 256 & 256 & $1 \times 10^{2}$ & 2 & 0.007813 & $1 \times 10^{7}$ & 32 & 32 & $1 \times 10^{8}$ \\
\hline PA409937 & 128 & 0.5 & $1 \times 10^{0}$ & 16 & 2 & $1 \times 10^{1}$ & 2 & 0.015625 & $1 \times 10^{1}$ & 8 & 0.03125 & $1 \times 10^{0}$ \\
\hline PAO1::lux & 2 & 0.007813 & $1 \times 10^{0}$ & 1 & 0.003906 & $1 \times 10^{0}$ & 32 & 0.125 & $1 \times 10^{0}$ & 1 & 0.003906 & $1 \times 10^{0}$ \\
\hline PAO1 & 1 & 0.003906 & $1 \times 10^{0}$ & 2 & 0.03125 & $1 \times 10^{0}$ & 1 & 0.003906 & $1 \times 10^{0}$ & 1 & 0.003906 & $1 \times 10^{0}$ \\
\hline
\end{tabular}

MIC in the presence of PAM2H is the lowest concentration of antibiotic with PAM2H where there was no visible bacterial growth as determined by checkerboard assay. Amount of PAM2H column is the PFU/mL of the corresponding antibiotic well. Cells are color-coded by the MIC value: red is resistant, yellow is intermediate, green is susceptible.

The FIC for each antibiotic, FIC $_{\mathrm{AB}}$, was calculated for the lowest concentration of antibiotic that could completely inhibit growth in the presence of the PAM2H cocktail using the equation: $\mathrm{FIC}_{\mathrm{AB}}=\mathrm{MIC}_{\mathrm{AB} \Phi} / \mathrm{MIC}_{\mathrm{AB}}$ (Table 4) [29]. As the standard error in the microdilution MIC assay is one dilution on either side of the MIC value, an $\mathrm{MIC}_{\mathrm{AB} \Phi}$ value greater than two-fold below the $\mathrm{MIC}_{\mathrm{AB}}$ would be considered a significant change in bacterial strain susceptibility to the antibiotic. FIC $\mathrm{AB}_{\mathrm{B}}$ was chosen over applying a standard FIC index because phages replicate in bacteria; thus, the phage concentration changes over time. Fifteen of 16 strains had a significant increase in susceptibility to at least one antibiotic in the presence of PAM2H, and 12 of those strains had increased susceptibility to all four antibiotics. This indicates that in vitro, PAM2H has the ability to significantly increase the sensitivity of MDR P. aeruginosa strains to multiple different antibiotics. This increase in susceptibility across multiple classes of antibiotics in the presence of phages is important clinically, as it would give more options for treatment regimens and would limit the use of "drugs of last resort" [25,30]. 
Table 4. FIC $\mathrm{AB}$ values for four antibiotics against 16 P. aeruginosa strains.

\begin{tabular}{ccccc}
\hline & \multicolumn{3}{c}{ FIC $_{\text {AB }}$} \\
\hline Isolate No. & CAZ & MEM & GEN & CIP \\
\hline MRSN321 & 0.002 & 0.004 & 0.004 & 0.039 \\
MRSN994 & 0.001 & 0.004 & 0.004 & 0.004 \\
MRSN2108 & 0.004 & 0.004 & 0.004 & 0.004 \\
MRSN5498 & 0.125 & 0.008 & 0.002 & 0.004 \\
MRSN5508 & 0.004 & 0.004 & 0.004 & 0.004 \\
MRSN5519 & 0.004 & 0.004 & 0.004 & 0.004 \\
MRSN6695 & 1 & 1 & 1 & 0.5 \\
MRSN8915 & 0.004 & 0.5 & 1 & 0 \\
MRSN11538 & 1 & 0.5 & 0.125 & 0.063 \\
MRSN12282 & 0.004 & 0.25 & 0.016 & 0.004 \\
MRSN15678 & 0.004 & 0.125 & 0.063 & 0.004 \\
MRSN16345 & 0.004 & 0.016 & 0.004 & 0.004 \\
MRSN23861 & 1 & 1 & 0.004 & 1 \\
MRSN409937 & 0.004 & 0.125 & 0.008 & 0.004 \\
PAO1::lux & 0.004 & 0.004 & 0.004 & 0.004 \\
PAO1 & 0.004 & 0.016 & 0.004 & 0.004 \\
\hline
\end{tabular}

$\mathrm{FIC}_{\mathrm{AB}}$ is an assessment of the change in a bacterial strain's susceptibility to an antibiotic in the presence of a phage and is obtained by dividing the new MIC of the antibiotic (in the presence of PAM2H) by the MIC of the antibiotic by itself. A value of less than 0.5 indicates a significant increase in the bacterial strain's susceptibility to the antibiotic and is highlighted in blue.

\subsection{PAM2H + CAZ Combination Treatment Enhances Efficacy in a Mouse Dorsal Wound Model}

The in vitro results described above revealed that the CAZ MIC for PAO1 was reduced 256-fold in the presence of PAM2H. We hypothesized that this significant increase in invitro efficacy would result in increased efficacy in vivo in a mouse dorsal wound model compared to antibiotic treatment alone. To test this hypothesis, mice were wounded dorsally and infected with PAO1::lux. Mice were then treated with either PBS (control), PAM2H phage cocktail, CAZ, or PAM2H and CAZ in combination, as described in Section 3. The CAZ treatment concentration was determined by calculating the mouse equivalent dose based on the $2 \mathrm{~g} /$ dose of CAZ recommended for treating complex infections [31]. On day $4,24 \mathrm{~h}$ after treatment was ceased, the radiance $\left(\mathrm{p} / \mathrm{s} / \mathrm{cm}^{2} / \mathrm{sr}\right)$ of the bioluminescent signal of PAO1::lux in the combo-treated mice appeared significantly reduced compared to the other groups, as shown in the heat maps in Figure 1. When quantified, the bioluminescence was significantly reduced compared to the other treatment groups (Figure 2), indicating a reduction in bacterial counts in the wounds of combo-treated mice.

To confirm these results, mice were euthanized on day 4, and wound tissues were collected and plated for colony forming units (CFU) (Figure 3). The PBS control mice had $\sim 10^{9} \mathrm{CFU}$ per wound at the time of collection. Phage-only and CAZ-only treated mice had a 1-2 log reduction, with CFU per wound at approximately $10^{7}$. The combo-treated wounds had a marked reduction in CFU compared to all groups, with no detectable CFU in seven out of the eight wounds collected, and a 5-log reduction in CFU compared to the PBS control for the remaining mouse wounds. These data indicate that the combination treatment resulted in a synergistic reduction in the bacterial burden compared to either treatment alone, as the median log reduction was greater than the sum of the median reductions of each monotherapy [23]. Additionally, all of the treatments had increased survival as compared to the PBS control-treated group. In CFU count experiments, only $47 \%$ of the PBS-treated mice survived to day 4 , whereas all of the mice in the treatment groups survived. 


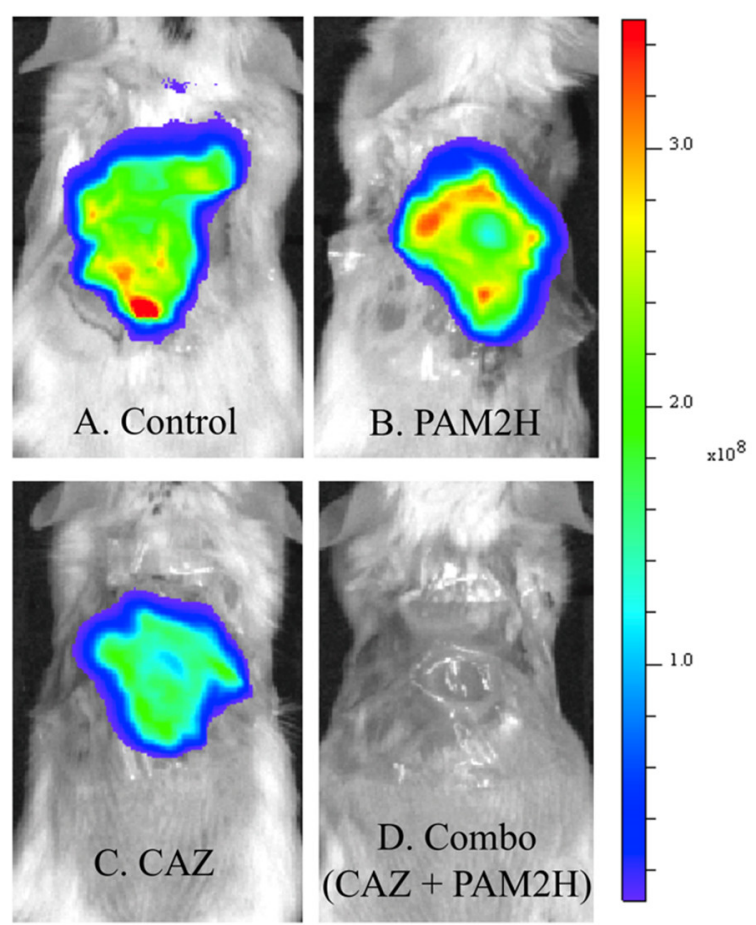

Figure 1. IVIS images showing the radiance $\left(\mathrm{p} / \mathrm{s} / \mathrm{cm}^{2} / \mathrm{sr}\right)$ of PAO1::lux bacteria in dorsal wounds of mice on day 4 post-surgery after completion of treatments. (A). IVIS of a mouse from the controltreated group receiving only PBS, (B). PAM2H (phage cocktail) only treated group, (C). CAZ only treated group, (D). combination treated group receiving both PAM2H and CAZ.

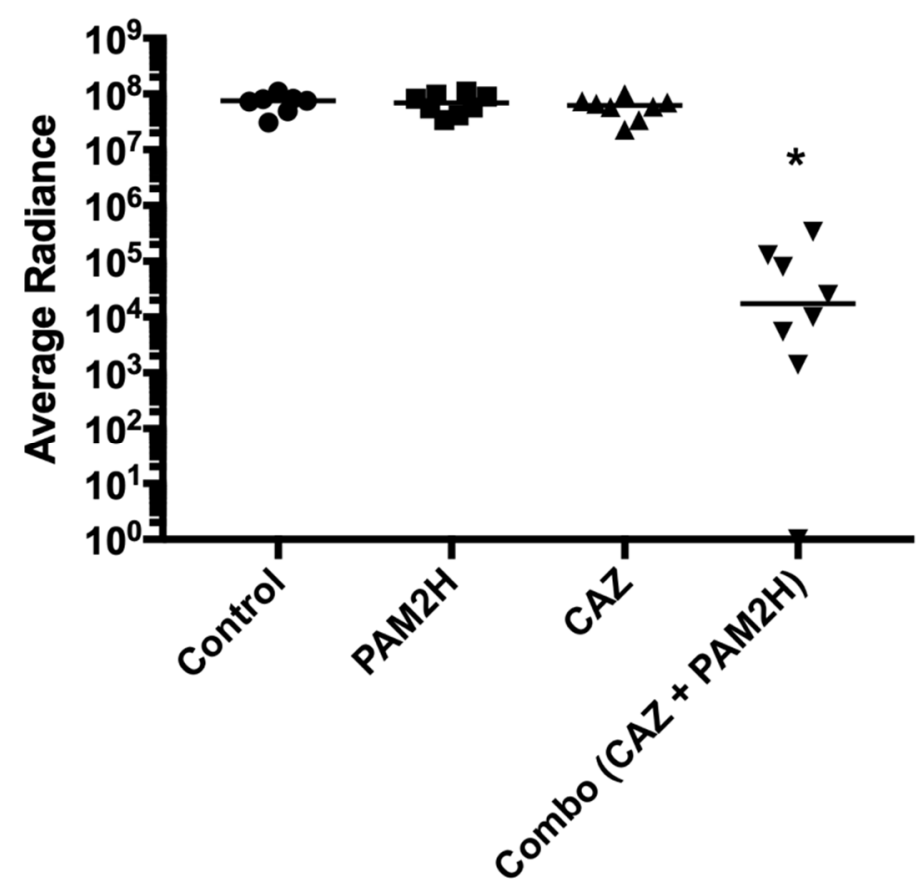

Figure 2. Quantification of the bacterial luminescence for mice from each treatment group as determined by IVIS on day 4 at the completion of treatment. ${ }^{*} p<0.05$. 


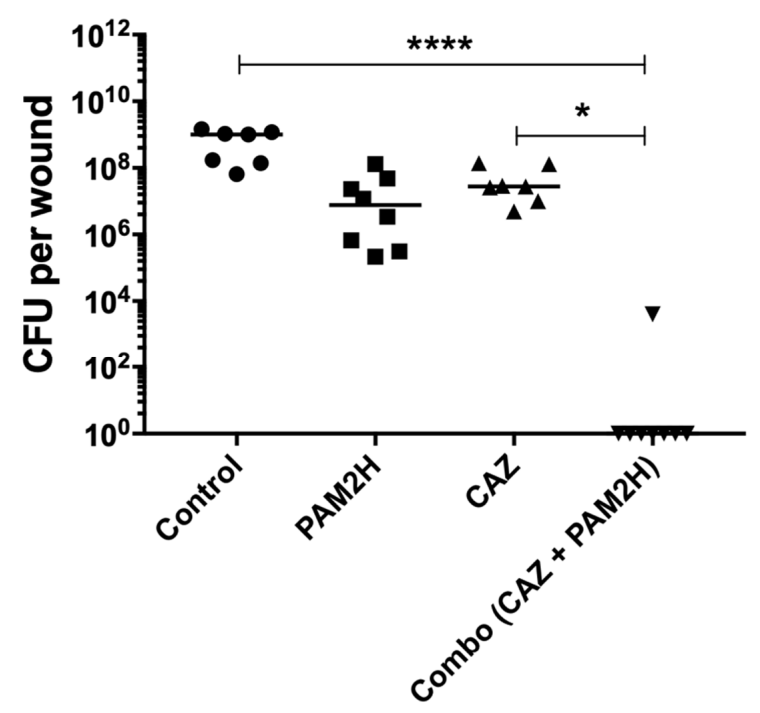

Figure 3. Colony forming units obtained from excised wound tissue on day 4 post treatment. ${ }^{*} p<0.05,{ }^{* * * *} p<0.0001$.

Finally, as a further assessment of the efficacy of this model, physical wound size was measured over the course of the 21-day experiment (Figure 4). Typically in this model, after the Tegaderm bandage is removed (day 7 for this study), the wound significantly increases in size, peaking at day 10 before contraction and healing begin [32]. The wounds of both CAZ- and combo-treated mice closed on day 21 of the experiment. On day 10 of this study, the wound size for the combo-treated group was significantly smaller than that in the control or in the other treatment groups $(p<0.005)$. Additionally, the median wound size on day 10 for this group was less than the median wound size on day 0 , meaning the wounds did not increase in size following Tegaderm removal, but began to contract and heal. This suggests that the combo treatment prevented the spread of bacteria into and necrosis of the surrounding tissue of the wound. While the final wound closure rate for the combination treatment was the same as that for the CAZ treatment, the reduced necrosis and lack of wound expansion indicate that combination treatment can help to prevent the spread of bacteria to other tissues and can reduce the amount of future scar tissue, leading to better clinical outcomes.

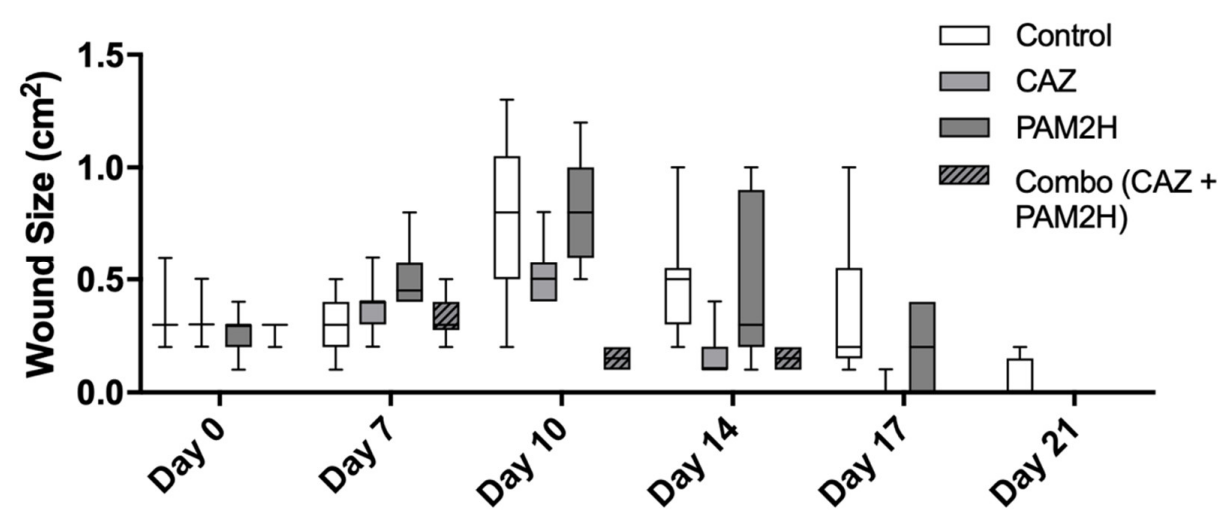

Figure 4. Mouse dorsal wound sizes as measured by an Aranz wound measurement device over 21 days. On day 10, the wound size for the combo-treated group was significantly smaller than that in the control or in the other treatment groups $(p<0.005)$, and the median wound size on day 10 for the combo group was less than the median wound size on day 0 , meaning the wounds had begun to contract and heal. 


\subsection{Recovered Strain Virulence in Wax Worms}

Several of the bacterial colonies recovered on day 4 from the above mouse wound experiments showed morphological differences from the parental strain PAO1::lux. Four isolates, $\mathrm{PH} 1$ to $\mathrm{PH} 4$, were selected from two mice in the PAM2H-only treatment group, four isolates, CA1 to CA4, were selected from two mice in the CAZ-only treatment groups, and two isolates, $\mathrm{CAPH} 1$ and $\mathrm{CAPH} 2$, were recovered from one mouse in the combo treatment group. The isolates obtained from the one combo-treated mouse wound had different morphologies. No colonies from the control group showed morphological differences from the parental strain. These PAO1::lux mutant isolates were assessed for virulence in the G. mellonella larva model. Decreased virulence was observed in four of the 10 mutants as compared to the original PAO1::lux control (Figure 5). All of the wax worms infected with wild type PAO1::lux died within $24 \mathrm{~h}$ of inoculation, while worms inoculated with mutant strains PH1, PH2, CA1, and CAPH1 demonstrated increased survival. Of the mutant strains, $\mathrm{PH} 2$ showed the greatest decrease in virulence as compared to PAO1::lux, with $80 \%$ survival 4 days post infection $(p<0.0001)$; PH1 and CAPH1 showed a 70\% survival $(p<0.0001)$. The CA1 mutant strain showed a $20 \%$ survival 4 days post infection; this increase in survival was not statistically significant. The decrease in virulence of some of the recovered strains suggests that while there were bacteria remaining in the mouse wounds after treatment, their ability to cause a robust infection was reduced. This was confirmed by the increased survival of mice in the treatment groups compared to the control group. This decrease in virulence was further investigated by sequencing the mutant strains to determine which virulence factors may be impacted by treatment with phage, antibiotics, or combination treatment.

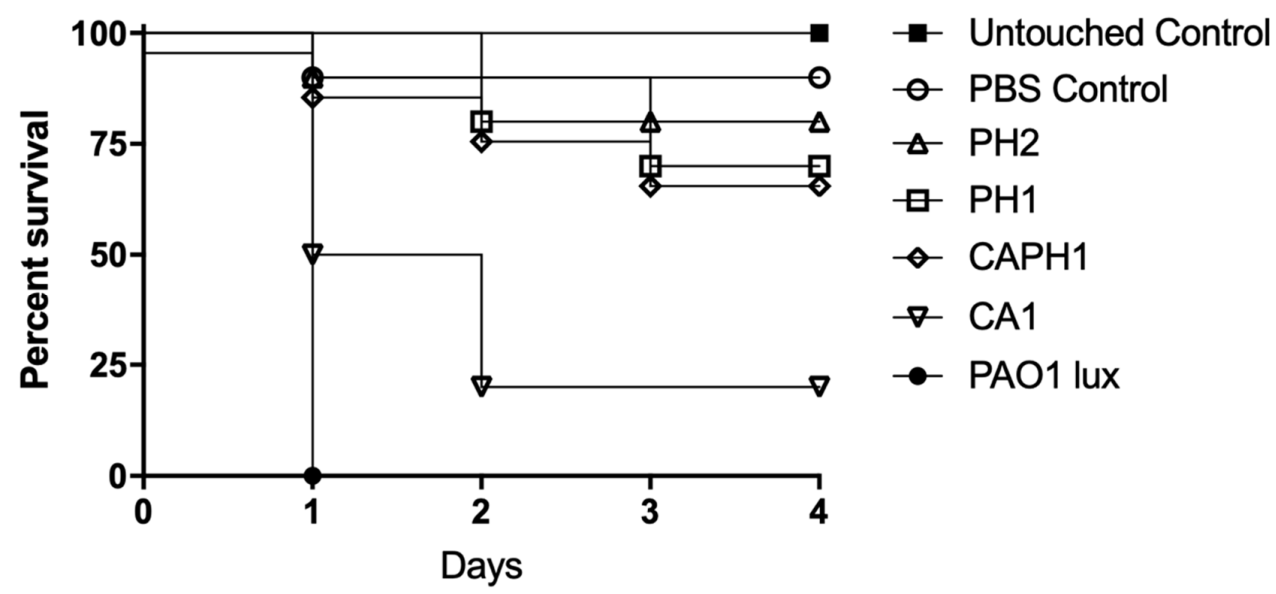

Figure 5. Kaplan-Meier survival curve for Galleria wax worms inoculated with PAO1::lux mutants recovered from mouse dorsal wounds post-treatment. Original PAO1::lux was used as a positive control, and an untouched group and PBS injected group served as negative controls. PH1 and PH2 were isolates obtained from mice in the phage-only treatment group. CA1 was collected from the CAZ-only treatment group, and CAPH1 was obtained from the combination treatment group. PH2, PH1, and CAPH1 showed a significant increase in survival compared to the PAO1::lux $(p<0.0001)$. Note: the survival curves for PH1 and CAPH1 were identical; thus, the survival curve for CAPH1 was moved below PH1 so that the symbols for each curve are discernible on the graph.

\subsection{Whole-Genome Sequencing of Recovered PAO1 Strains}

Genomic DNA from PAO1::lux variants recovered from the mouse dorsal wound experiments post treatment was sequenced to compare to the original PAO1::lux. Every strain from the phage-only treatment had mutations to at least one gene coding for a known phage receptor. However, the bacteria recovered from the mouse given combination phageantibiotic treatment had no SNP changes in typical phage receptor genes (Table 5). This suggests that treatment with phages and antibiotics concurrently is a better option than 
treatment with phages alone, because it may reduce the emergence of phage resistance. Additionally, PH2 and CAPH1 were observed to be missing the mexX gene due to nonsynonymous large deletion events. The mexX gene is an antimicrobial resistance (AMR) gene encoding a periplasmic protein that is part of a drug efflux pump. None of the strains from the antibiotic-only treatment had this mutation. One or more of the phages in the PAM2H cocktail may select against drug efflux pumps, helping to re-sensitize P. aeruginosa to antibiotic treatment. This mutation was correlated with a significant decrease in strain virulence as seen in Figure 5, indicating that a functional MexX protein may be important for virulence in PAO1 [33].

Table 5. Summary of observed small variant (SNPs and short indels) with respect to progenitor strain PAO1::lux observed in recovered mouse mutant strains and whether the mutation impacts a known phage receptor.

\begin{tabular}{|c|c|c|c|c|c|c|c|c|c|c|c|c|c|}
\hline \multirow[t]{2}{*}{ Product $^{1}$} & \multirow[t]{2}{*}{ Mutation $^{2}$} & \multirow[t]{2}{*}{ Impact $^{3}$} & \multirow{2}{*}{$\begin{array}{c}\text { Known } \\
\text { Phage } \\
\text { Receptor }\end{array}$} & \multicolumn{10}{|c|}{ PAO1::lux Mutant Isolates } \\
\hline & & & & PH1 & PH2 & PH3 & PH4 & CA1 & CA2 & CA3 & CA4 & CAPH1 & CAPH2 \\
\hline $\begin{array}{l}\text { type } 4 \text { fimbrial biogenesis } \\
\text { outer membrane protein } \\
\text { PilQ }\end{array}$ & $\begin{array}{c}\mathrm{SNP} \\
(\mathrm{A}>\mathrm{C})\end{array}$ & Thr605Pro & Yes & + & & & & & & & & & \\
\hline $\begin{array}{l}\text { B-band O-antigen } \\
\text { polymerase }\end{array}$ & $\begin{array}{l}\text { Insertion } \\
\text { (A) }\end{array}$ & Thr46 (fs) & Yes & & & + & & & & & & & \\
\hline $\begin{array}{l}\text { B-band O-antigen } \\
\text { polymerase }\end{array}$ & $\begin{array}{l}\text { SNP } \\
(\mathrm{A}>\mathrm{G})\end{array}$ & Tyr249Cys & Yes & & & & + & & & & & & \\
\hline $\begin{array}{l}\text { type } 4 \text { fimbrial biogenesis } \\
\text { protein PilY1 }\end{array}$ & $\begin{array}{l}\text { Deletion } \\
\text { (AGACC- } \\
\text { AGCTT) }\end{array}$ & $\mathrm{G} \ln 520(\mathrm{fs})$ & Yes & & & + & & & & & & & \\
\hline $\begin{array}{c}\text { type } 4 \text { fimbrial biogenesis } \\
\text { protein PilB }\end{array}$ & $\begin{array}{l}\text { Deletion } \\
\text { (A) }\end{array}$ & His414 (fs) & Yes & & & & + & & & & & & \\
\hline $\begin{array}{l}\text { type } 4 \text { fimbrial biogenesis } \\
\text { protein PilB }\end{array}$ & $\begin{array}{l}\text { Deletion } \\
\text { (CGGA) }\end{array}$ & $\operatorname{Arg} 258(\mathrm{fs})$ & Yes & & + & & & & & & & & \\
\hline $\begin{array}{l}\text { glucose-6-phosphate } \\
\text { isomerase }\end{array}$ & $\begin{array}{l}\text { Insertion } \\
\text { (A) }\end{array}$ & Thr219 (fs) & No & + & & & & & & & & & \\
\hline oxidoreductase & $\begin{array}{c}\text { SNP } \\
(\mathrm{T}>\mathrm{A})\end{array}$ & Ser133Thr & No & + & + & + & + & + & + & + & + & + & + \\
\hline
\end{tabular}

${ }^{1}$ Gene product in which a mutation was observed. Gene products listed on multiple lines are indicative of distinct mutations being observed across isolates. ${ }^{2}$ Description of the mutation event that was observed (Insertion, Deletion, or Single Nucleotide Polymorphism (SNP)). ${ }^{3}$ Impact of the mutation on the translated protein product. (fs): a frameshift has occurred. ${ }^{4}$ Whether or not the product impacted is a known bacteriophage receptor. + symbol marks the gene mutation that each strain contained.

\section{Materials and Methods}

\subsection{Bacterial Strains and Bacteriophages}

P. aeruginosa strain PAO1, a wound isolate, was selected because of its extensive characterization and wide use as a laboratory strain [34]. PAO1::lux was created by cloning the luxCDABE luciferase-production operon into the chromosome of PAO1 using a Tn7 plasmid, as previously described [35]. For in vitro testing, 14 additional MDR P. aeruginosa clinical strains susceptible to the PAM2H bacteriophage cocktail were selected from a 100-strain panel of genetically diverse isolates generously provided by the Multidrugresistant organism Repository and Surveillance Network (MRSN, WRAIR). The P. aeruginosa phage cocktail PAM2H contains equal concentrations of five unique phages: EPa5, EPa11, EPa15, EPa22, and EPa43 [36] (Table 6).

Table 6. P. aeruginosa phages in the PAM2H cocktail.

\begin{tabular}{lll}
\hline Phage Name & Family & Genus \\
\hline EPa5 & Siphoviridae & Abidjanvirus \\
EPa11 & Myoviridae & Pbunavirus \\
EPa15 & Myoviridae & Pbunavirus \\
EPa22 & Myoviridae & Pbunavirus \\
EPa43 & Siphoviridae & Abidjanvirus \\
\hline
\end{tabular}




\subsection{Bacteriophage Isolation and Cocktail Preparation}

Bacteriophages were propagated on P. aeruginosa strains PAO1 or MRSN1680. The host bacteria were grown in heart infusion broth (HIB; Becton, Dickinson and Co., Franklin Lakes, NJ) supplemented with $5 \mathrm{mM}$ calcium chloride and incubated in a vented culture flask at $37^{\circ} \mathrm{C}$ and $200 \mathrm{rpm}$. Phage stock lysate was added to $250 \mathrm{~mL}$ of an early exponential phase bacterial culture grown in HIB (OD600 of $0.1-0.2 ; 10^{8}$ colony forming units $/ \mathrm{mL}$ ) at a multiplicity of infection of $0.1\left(10^{7}\right.$ plaque forming units $\left./ \mathrm{mL}\right)$ and incubated in a $500-\mathrm{mL}$ plastic Erlenmeyer flask at $37^{\circ} \mathrm{C}$ and $200 \mathrm{rpm}$ overnight. The phage and bacterial debris were pelleted by centrifugation at $5500 \times g$ overnight, and then the phage was purified with 1-octanol (Sigma, St. Louis, MO, USA) washes and a cesium chloride (Sigma) density gradient. The final phage concentrate was exchanged into gelatin-free SM buffer (100 mM sodium chloride, $50 \mathrm{mM}$ Tris- $\mathrm{HCl}, \mathrm{pH} 7.5$, and $10 \mathrm{mM}$ magnesium sulfate) by serial washes in a protein concentrator (Thermo Fisher, Waltham, MA, USA). Endotoxin levels were tested with the Endosafe-PTS device (Charles River Laboratories, Wilmington, MA, USA), and if needed, further purified using EndoTrap bulk resin (Hyglos $\mathrm{GmbH}$, Bernried am Starnberger See, Germany) according to the manufacturer's protocol, to ensure that the endotoxin level was below $500 \mathrm{EU}$ per $10^{9} \mathrm{PFU}$ (plaque-forming units).

\subsection{Antibiotics}

Antibiotics were selected from three classes based on their mechanism of action and clinical relevance: ceftazidime, generic name Tazicef (CAZ; Hospira, Lake Forest, IL, USA), ciprofloxacin (CIP; Sigma), gentamicin (GEN; Sigma), and meropenem (MEM; Sigma). Antibiotics were dissolved at time of use in a $10 \mathrm{mg} / \mathrm{mL}$ stock in $1 \times$ PBS (Thermo Fisher) except for ciprofloxacin which was dissolved in $0.1 \mathrm{~N} \mathrm{HCl}$ (Sigma). Stocks were further diluted for treatments in $1 \times$ PBS.

\subsection{Minimum Inhibitory Concentration Assays}

Assays to determine the minimum inhibitory concentration (MIC) for antibiotics and bacteriophages were performed in accordance with the Clinical and Laboratory Standards Institute (CLSI) broth microdilution protocol [37] with the following modifications for the phage assay [38]. Briefly, to make the bacterial inoculum, individual colonies from test strains grown overnight on 1.5\% HIB agar plates were suspended in deionized (DI) water (Thermo Fisher) to $0.5 \mathrm{McFarland}$ standard, and $10 \mu \mathrm{L}$ of the inoculated water was transferred to $11 \mathrm{~mL}$ of cation-adjusted Mueller Hinton Broth (CAMHB) (Thermo Fisher). To prepare the phage treatment, the PAM2H phage cocktail was diluted serially, 1:10 from $2 \times 10^{9} \mathrm{PFU} / \mathrm{mL}$ to $2 \mathrm{PFU} / \mathrm{mL}$ in CAMHB. Fifty microliters of bacterial inoculum was added to wells of a 96-well microtiter plate, and $50 \mu \mathrm{L}$ of phage dilutions was added to appropriate wells. One row of bacterial inoculum received no phages to serve as a positive growth control, and one row of only CAMHB served as a negative growth control. Plates were incubated at $37^{\circ} \mathrm{C}$ overnight. The MIC for each phage or antibiotic was determined as the lowest concentration of treatment with no visible bacterial growth.

\subsection{Fractional Inhibitory Concentration Assays}

The fractional inhibitory concentrations (FIC) of antibiotics (CAZ, CIP, GEN, and MEM) in the presence of PAM2H were determined using the checkerboard method [39,40]. Briefly, antibiotics were serially diluted $1: 2$ from $1024 \mu \mathrm{g} / \mathrm{mL}$ down to $0.007813 \mu \mathrm{g} / \mathrm{mL}$ in CAMHB. PAM2H was serially diluted 1:10 starting at $4 \times 10^{9} \mathrm{PFU} / \mathrm{mL}$ in CAMHB. To make the bacterial inoculum, individual colonies from test strains grown overnight on HIB agar plates were suspended in DI water to 0.5 McFarland standard, and $10 \mu \mathrm{L}$ of the inoculated water was transferred to $11 \mathrm{~mL}$ of CAMHB. For each strain, $25 \mu \mathrm{L}$ of antibiotic in decreasing concentrations from left to right was added to columns 1 to 10 starting at $8 \times$ MIC. Twenty-five microliters of PAM2H was added to each row of columns $1-10$, decreasing from top to bottom starting at $40 \times$ MIC. Fifty microliters of bacterial inoculate was added to each well in columns $1-11$, and $100 \mu \mathrm{L}$ of only CAMHB medium 
was aliquoted to each well in column 12 as a negative growth control. Plates were incubated at $37^{\circ} \mathrm{C}$ overnight. The MIC for the antibiotic in the presence of the phage was determined as the lowest concentration of antibiotic with no visible bacterial growth. Changes in antibiotic MIC in the presence of the phage greater than twofold (standard error of the assay) compared to the antibiotic MIC were considered significant.

\subsection{Assessment of Phage Antibiotic Combination Treatment in a P. aeruginosa Mouse Wound Model}

The PAM2H + CAZ combination treatment was assessed in our previously described mouse wound model [32,41]. Six-week-old female BALB/c mice were anesthetized with $130 \mathrm{mg} / \mathrm{kg}$ ketamine and $10 \mathrm{mg} / \mathrm{kg}$ xylazine, their backs were shaved, and a 6-mm, fullthickness wound was created on their dorsal side. Each wound was inoculated with approximately $1 \times 10^{7} \mathrm{CFU}$ (colony-forming units) of PAO1::lux and covered with a Tegaderm $^{\mathrm{TM}}$ bandage (3M, St. Paul, MN, USA). Mice were single-housed from day 0 (inoculation) through day 9. There were four groups of mice in the experiment: PBS control, phage treatment only, CAZ treatment only, and phage + CAZ (combo) treatment (Table 7). The phage and CAZ were both suspended in PBS to the required titer/concentration. Treatments were given as follows (Table 7): For PBS control, mice received $25 \mu \mathrm{L}$ of PBS topically under the Tegaderm ${ }^{\mathrm{TM}}$ dressing, on top of the wound, once a day, and a dose of PBS intraperitoneally (IP) at $5 \mu \mathrm{L} / \mathrm{g}$ body weight twice a day. For phage treatment only, mice received $25 \mu \mathrm{L}$ of $1 \times 10^{8}$ PFU phage topically under the Tegaderm ${ }^{\mathrm{TM}}$ dressing, on top of the wound, once a day, and a dose of PBS IP at $5 \mu \mathrm{L} / \mathrm{g}$ body weight twice a day. For CAZ treatment only, mice received $25 \mu \mathrm{L}$ of PBS topically under the Tegaderm ${ }^{\mathrm{TM}}$ dressing, on top of the wound, once a day, and a $410 \mathrm{mg} / \mathrm{kg}$ dose of CAZ IP at $5 \mu \mathrm{L} / \mathrm{g}$ body weight twice a day. For combo treatment, mice received $25 \mu \mathrm{L}$ of $1 \times 10^{8}$ PFU phage topically under the Tegaderm ${ }^{\mathrm{TM}}$ dressing, on top of the wound, once a day, and a $410 \mathrm{mg} / \mathrm{kg}$ dose of CAZ IP at $5 \mu \mathrm{L} / \mathrm{g}$ body weight twice a day.

Table 7. Treatment type and frequency for mouse groups infected with PAO1::lux.

\begin{tabular}{ccc}
\hline Treatment Groups & \multicolumn{2}{c}{ Treatment Location } \\
\hline & Topical $(25 \mu \mathrm{L})$ & Intraperitoneal $(\mathbf{5} \mu \mathrm{L} / \mathbf{g})$ \\
\hline Phage-Treated Group & $1 \times$ per day & $2 \times$ per day \\
Ceftazidime-Treated Group & PAM2H cocktail & PBS \\
Combination-Treated Group & PBS & Ceftazidime (CAZ) \\
Control-Treated Group & PAM2H cocktail & Ceftazidime (CAZ) \\
\hline
\end{tabular}

Treatments were administered starting at $4 \mathrm{~h}$ post-infection. Phage treatments were given at $4 \mathrm{~h}$ (day 0 ), and then once daily on days $1-3$, for a total of four doses of the phage. CAZ treatments were given at $4 \mathrm{~h}$ (day 0 ), and then twice daily, every $12 \mathrm{~h}$, on days $1-3$, for a total of seven doses of CAZ. On day 7 post-infection, Tegaderm ${ }^{\mathrm{TM}}$ dressings were removed, and the wounds were left exposed to air for the remainder of the experiment.

Multiple outcomes were measured to assess the above treatments, including weight and clinical score, wound size and healing, and the bioluminescent signal and CFU of the bacterial burden in the wound. Mouse weights and clinical scores were monitored and recorded daily through day 6 of the experiment. An in vivo imaging system (IVIS; PerkinElmer, Waltham, MA, USA) was used to measure the bioluminescent signal of PAO1::lux as a means to visualize and perform relative quantification of the bacterial burden in the wound beds over the course of the experiment (control mice $n=7$, treatment groups $n=8$ ). To do so, mice were anesthetized with isoflurane gas and placed dorsal side up, inside the IVIS chamber. Bioluminescence measurements were taken with an exposure time of $1 \mathrm{~min}$ on days 1 and 4. Using Living Image Software version 4.2 (PerkinElmer), pictures were analyzed and bioluminescence was quantified. To determine the average 
radiance, each wound was measured using a region of interest (ROI) of $2.3 \mathrm{~cm}^{2}$. To confirm the IVIS data, the bacteria in the wound beds were quantified on day 4 post-infection by excising the wounds and plating for $\mathrm{CFU}$ (control mice $n=7$, treatment groups $n=8$ ). To do this, the mice were humanely euthanized using $\mathrm{CO}_{2}$ exposure followed by cervical dislocation, and the wound and surrounding tissue $(\sim 3 \mathrm{~mm})$ were excised and placed in PBS. The tissue was homogenized, 10-fold serially diluted, and plated on HIB agar. $\mathrm{CFU}$ were enumerated following overnight incubation at $37^{\circ} \mathrm{C}$. In additional studies, the wound size was measured and compared for all mice in all treatment groups using a Silhouette wound measurement device (Aranz Medical Ltd., Christchurch, New Zealand) on days $0,10,14,17$, and 21 post-infection (control $n=9$, PAM2H $n=10$, CAZ $n=20$, combo $n=10$ ). Statistical analyses were completed using a Kruskal-Wallis test followed by Dunn's multiple comparison test. Significance was established at $p<0.05$.

Research was conducted in an AAALACi accredited program in compliance with the Animal Welfare Act and other federal statutes and regulations relating to animals and experiments involving animals and adhered to principles stated in the Guide for the Care and Use of Laboratory Animals [42]. The study protocol was reviewed and approved by the Walter Reed Army Institute of Research/Naval Medical Research Center Institutional Animal Care and Use Committee in compliance with all applicable Federal regulations governing the protection of animals in research.

\subsection{Assessment of P. aeruginosa Strain Virulence in Galleria mellonella Larvae}

Colonies of $P$. aeruginosa PAO1::lux isolated from mouse wounds after treatment with PAM2H phages only $(n=4)$, CAZ only $(n=4)$, or the PAM2H + CAZ combination $(n$ $=2$ ) displayed different phenotypes and colony morphologies compared to the parental strain. To determine if any of these colonies were attenuated, we assessed bacterial virulence in a G. mellonella larva (wax worm) model of infection, as previously described [43]. $P$. aeruginosa strains were grown to the exponential phase, washed, and resuspended in PBS to approximately $1 \times 10^{7} \mathrm{CFU}$ per $\mathrm{mL}$. Wax worms (Vanderhorst, Inc., St. Marys, OH, USA) in the final-instar larval stage and weighing 200-300 mg were saved and housed in clean plastic Petri dishes, 10 worms per group. Worms in each group were inoculated with $5 \mu \mathrm{L}$ of one bacterial strain into their last left proleg using a 10- $\mu \mathrm{L}$ Hamilton syringe (Fisher Scientific, Pittsburgh, PA, USA). After infection, worms were incubated in plastic Petri dishes at $37^{\circ} \mathrm{C}$ and monitored for death over four days. Worms were considered dead when they displayed no movement in response to tactile stimuli. Two control groups were included in the experiment, an "untouched" control group that did not receive any injections, to ensure the health of the worms after shipping, and a PBS control group that was injected with PBS instead of bacteria, to control for detrimental effects from injection. Survival curves were compared using the Mantel-Cox test with Bonferroni's correction for multiple comparisons. Significance was established at $p<0.05$.

\subsection{P. aeruginosa DNA Isolation and Whole-Genome Sequencing}

DNA was extracted using the DNeasy UltraClean Microbial Kit (Qiagen, Germantown, MD, USA), and libraries were constructed using the KAPA HyperPlus Library preparation kit (Roche Diagnostics, Indianapolis, IN, USA). Libraries were quantified using the KAPA Library Quantification Kit-Illumina/Bio-Rad iCycler ${ }^{\mathrm{TM}}$ (Roche Diagnostics). Sequencing was performed using an Illumina MiSeq desktop sequencer (Illumina Inc., San Diego, CA, USA) with a MiSeq Reagent Kit v3 (600 cycle) (Illumina Inc.).

Species identification and contamination detection were performed from sequencing reads using Kraken2 [44]. Reads were trimmed for adapter content and quality with BBduk [45] followed by de novo assembly using Newbler v2.9 [46]. Antimicrobial resistance genes were annotated using a combination of ARIBA [47] and AMRFinderPlus [48]. MLST assignment was performed using multilocus sequence typing [49] against the relevant schema hosted by pubMLST [50]. The progenitor PAO1::lux draft assembly was errorcorrected and annotated using a combination of Snippy [51], Pilon [52], and Prokka [53] for 
use as the SNP analysis reference genome. Snippy was used to identify single nucleotide polymorphisms (SNPs) in each of the passaged isolates with respect to the annotated reference. Further comparative genomic analyses were performed using Geneious Prime (Biomatters, Auckland, New Zealand).

\section{Conclusions}

Increasing threats from MDR pathogens have made it necessary to explore alternative treatment options. Phage-antibiotic combination therapy is a promising candidate for combating MDR P. aeruginosa infections. The studies described here show that using $P$. aeruginosa phages in combination with different classes of antibiotics was not only efficacious, but synergistic in the reduction of bacterial populations and resulted in the re-sensitization of MDR P. aeruginosa to antibiotics. Bacteria remaining in mouse wounds following combination treatment were shown to have mutations in virulence-associated drug efflux pump genes, suggesting that the only way for the bacteria to evade the combination treatment was to become avirulent, which would allow the host immune system to clear the infection. Additionally, while bacteria remaining in the phage-only treated mouse wounds had mutations for phage receptors, and were thus resistant to phage infection, none of these mutations was found in the combination treatment bacteria, suggesting that the combination treatment reduced the incidence of the bacteria becoming resistant to the phage treatment. Taken together, these data show the synergy that exists with phageantibiotic combination treatment and support the idea that these treatment regimens would enhance the efficacy of both phages and antibiotics in a human patient and would result in better clinical outcomes.

Author Contributions: Conceptualization, S.D.T. and A.C.J.; Data curation, E.E. and A.C.J.; Formal analysis, E.E., B.W.C. and A.C.J.; Funding acquisition, S.D.T. and A.C.J.; Investigation, E.E., H.R.F. and A.C.J.; Methodology, E.E., H.R.F., B.W.C., A.M.W. and Y.H.; Project administration, A.C.J.; Supervision, M.P.N., A.A.F. and A.C.J.; Validation, E.E., H.R.F., B.W.C., A.M.W. and Y.H.; Visualization, E.E. and A.C.J.; Writing—original draft, E.E., H.R.F., B.W.C. and A.C.J.; Writing-review \& editing, E.E., M.P.N., A.A.F. and A.C.J. All authors have read and agreed to the published version of the manuscript.

Funding: This research was funded in part by the US DoD Peer-Reviewed Medical Research Program, grant number PR161279.

Institutional Review Board Statement: Research was conducted under an approved animal use protocol in an AAALACi-accredited facility in compliance with the Animal Welfare Act and other federal statutes and regulations relating to animals and experiments involving animals and adheres to principles stated in the Guide for the Care and Use of Laboratory Animals, NRC Publication, 2011 edition.

Informed Consent Statement: Not applicable.

Data Availability Statement: Data sharing not applicable.

Acknowledgments: Material has been reviewed by the Walter Reed Army Institute of Research. There is no objection to its presentation and/or publication. The opinions or assertions contained herein are the private views of the author, and are not to be construed as official, or as reflecting true views of the Department of the Army or the Department of Defense. We acknowledge the staff at the Walter Reed Army Institute of Research-Multidrug-resistant organism Repository and Surveillance Network (WRAIR/MRSN) for whole-genome sequencing and bioinformatic analyses, visualization, interpretation, and reporting. We also thank the WRAIR Wound Infections Department animal team for their assistance in the mouse wound model studies.

Conflicts of Interest: The authors declare no conflict of interest.

\section{References}

1. Lobanovska, M.; Pilla, G. Penicillin's Discovery and Antibiotic Resistance: Lessons for the Future? Yale J. Boil. Med. 2017, 90, 135-145.

2. Durand, G.A.; Raoult, D.; Dubourg, G. Antibiotic discovery: History, methods and perspectives. Int. J. Antimicrob. Agents 2019, 53, 371-382. [CrossRef] 
3. Davies, J.; Davies, D. Origins and Evolution of Antibiotic Resistance. Microbiol. Mol. Biol. Rev. 2010, 74, 417-433. [CrossRef]

4. Friedman, N.; Temkin, E.; Carmeli, Y. The negative impact of antibiotic resistance. Clin. Microbiol. Infect. 2016, 22, 416-422. [CrossRef]

5. Boucher, H.W.; Talbot, G.H.; Bradley, J.S.; Edwards, J.E.; Gilbert, D.; Rice, L.B.; Scheld, M.; Spellberg, B.; Bartlett, J. Bad Bugs, No Drugs: No ESKAPE! An Update from the Infectious Diseases Society of America. Clin. Infect. Dis. 2009, 48, 1-12. [CrossRef]

6. Pendleton, J.N.; Gorman, S.P.; Gilmore, B.F. Clinical relevance of the ESKAPE pathogens. Expert Rev. Anti-Infect. Ther. 2013, 11, 297-308. [CrossRef]

7. Tillotson, G.S.; Zinner, S.H. Burden of antimicrobial resistance in an era of decreasing susceptibility. Expert Rev. Anti-Infect. Ther. 2017, 15, 663-676. [CrossRef] [PubMed]

8. Lister, P.D.; Wolter, D.J.; Hanson, N.D. Antibacterial-Resistant Pseudomonas aeruginosa: Clinical Impact and Complex Regulation of Chromosomally Encoded Resistance Mechanisms. Clin. Microbiol. Rev. 2009, 22, 582-610. [CrossRef]

9. Livermore, D.M. Multiple Mechanisms of Antimicrobial Resistance in Pseudomonas aeruginosa: Our Worst Nightmare? Clin. Infect. Dis. 2002, 34, 634-640. [CrossRef] [PubMed]

10. Tacconelli, E.; Carrara, E.; Savoldi, A.; Harbarth, S.; Mendelson, M.; Monnet, D.L.; Pulcini, C.; Kahlmeter, G.; Kluytmans, J.; Carmeli, Y.; et al. Discovery, research, and development of new antibiotics: The WHO priority list of antibiotic-resistant bacteria and tuberculosis. Lancet Infect. Dis. 2018, 18, 318-327. [CrossRef]

11. Wright, G.D. Antibiotic Adjuvants: Rescuing Antibiotics from Resistance. Trends Microbiol. 2016, 24, 862-871. [CrossRef]

12. Summers, W.C. Bacteriophage Therapy. Annu. Rev. Microbiol. 2001, 55, 437-451. [CrossRef]

13. Kortright, K.E.; Chan, B.K.; Koff, J.L.; Turner, P.E. Phage Therapy: A Renewed Approach to Combat Antibiotic-Resistant Bacteria. Cell Host Microbe 2019, 25, 219-232. [CrossRef] [PubMed]

14. Pires, D.P.; Boas, D.P.A.V.; Sillankorva, S.; Azeredo, J. Phage Therapy: A Step Forward in the Treatment of Pseudomonas aeruginosa Infections. J. Virol. 2015, 89, 7449-7456. [CrossRef]

15. Hall, A.R.; De Vos, D.; Friman, V.-P.; Pirnay, J.-P.; Buckling, A. Effects of Sequential and Simultaneous Applications of Bacteriophages on Populations of Pseudomonas aeruginosaIn Vitroand in Wax Moth Larvae. Appl. Environ. Microbiol. 2012, 78, 5646-5652. [CrossRef]

16. Debarbieux, L.; LeDuc, D.; Maura, D.; Morello, E.; Criscuolo, A.; Grossi, O.; Balloy, V.; Touqui, L. Bacteriophages Can Treat and PreventPseudomonas aeruginosaLung Infections. J. Infect. Dis. 2010, 201, 1096-1104. [CrossRef]

17. Morello, E.; Saussereau, E.; Maura, D.; Huerre, M.; Touqui, L.; Debarbieux, L. Pulmonary Bacteriophage Therapy on Pseudomonas aeruginosa Cystic Fibrosis Strains: First Steps Towards Treatment and Prevention. PLoS ONE 2011, 6, e16963. [CrossRef] [PubMed]

18. Alemayehu, D.; Casey, P.G.; McAuliffe, O.; Guinane, C.M.; Martin, J.G.; Shanahan, F.; Coffey, A.; Ross, R.P.; Hill, C. Bacteriophages $\phi$ MR299-2 and $\phi N H-4$ Can Eliminate Pseudomonas aeruginosa in the Murine Lung and on Cystic Fibrosis Lung Airway Cells. mBio 2012, 3, e00029-12. [CrossRef]

19. Tiwari, B.R.; Kim, S.; Rahman, M.; Kim, J. Antibacterial efficacy of lytic Pseudomonas bacteriophage in normal and neutropenic mice models. J. Microbiol. 2011, 49, 994-999. [CrossRef] [PubMed]

20. Furfaro, L.L.; Payne, M.S.; Chang, B.J. Bacteriophage Therapy: Clinical Trials and Regulatory Hurdles. Front. Cell. Infect. Microbiol. 2018, 8, 376. [CrossRef] [PubMed]

21. Tagliaferri, T.L.; Jansen, M.; Horz, H.-P. Fighting Pathogenic Bacteria on Two Fronts: Phages and Antibiotics as Combined Strategy. Front. Cell. Infect. Microbiol. 2019, 9, 22. [CrossRef] [PubMed]

22. Oechslin, F.; Piccardi, P.; Mancini, S.; Gabard, J.; Moreillon, P.; Entenza, J.M.; Resch, G.; Que, Y.-A. Synergistic interaction between phage therapy and antibiotics clears Pseudomonas aeruginosa infection in endocarditis and reduces virulence. J. Infect. Dis. 2016, 215, 703-712. [CrossRef]

23. Chaudhry, W.N.; Concepción-Acevedo, J.; Park, T.; Andleeb, S.; Bull, J.J.; Levin, B.R. Synergy and Order Effects of Antibiotics and Phages in Killing Pseudomonas aeruginosa Biofilms. PLoS ONE 2017, 12, e0168615. [CrossRef]

24. Hagens, S.; Habel, A.; Bläsi, U. Augmentation of the Antimicrobial Efficacy of Antibiotics by Filamentous Phage. Microb. Drug Resist. 2006, 12, 164-168. [CrossRef]

25. Chan, B.K.; Sistrom, M.; Wertz, J.E.; Kortright, K.E.; Narayan, D.; Turner, P.E. Phage selection restores antibiotic sensitivity in MDR Pseudomonas aeruginosa. Sci. Rep. 2016, 6, 26717. [CrossRef]

26. Chan, B.K.; E Turner, P.; Kim, S.; Mojibian, H.R.; A Elefteriades, J.; Narayan, D. Phage treatment of an aortic graft infected with Pseudomonas aeruginosa. Evol. Med. Public Health 2018, 2018, 60-66. [CrossRef] [PubMed]

27. Khawaldeh, A.; Morales, S.; Dillon, B.; Alavidze, Z.; Ginn, A.N.; Thomas, L.; Chapman, S.J.; Dublanchet, A.; Smithyman, A.; Iredell, J.R. Bacteriophage therapy for refractory Pseudomonas aeruginosa urinary tract infection. J. Med. Microbiol. 2011, 60, 1697-1700. [CrossRef]

28. CLSI. Performance Standards for Antimicrobial Susceptibility Testing, 30th ed.; Clinical and Laboratory Standards Institute: Wayne, PA, USA, 2020.

29. Meletiadis, J.; Pournaras, S.; Roilides, E.; Walsh, T.J. Defining Fractional Inhibitory Concentration Index Cutoffs for Additive Interactions Based on Self-Drug Additive Combinations, Monte Carlo Simulation Analysis, and In Vitro-In Vivo Correlation Data for Antifungal Drug Combinations against Aspergillus fumigatus. Antimicrob. Agents Chemother. 2009, 54, 602-609. [CrossRef] 
30. Buehrle, D.J.; Shields, R.K.; Clarke, L.G.; Potoski, B.A.; Clancy, C.J.; Nguyen, M.H. Carbapenem-Resistant Pseudomonas aeruginosa Bacteremia: Risk Factors for Mortality and Microbiologic Treatment Failure. Antimicrob. Agents Chemother. $2016,61$. [CrossRef]

31. Nair, A.B.; Jacob, S. A simple practice guide for dose conversion between animals and human. J. Basic Clin. Pharm. 2016, 7, 27-31. [CrossRef] [PubMed]

32. Thompson, M.G.; Black, C.C.; Pavlicek, R.L.; Honnold, C.L.; Wise, M.C.; Alamneh, Y.A.; Moon, J.K.; Kessler, J.L.; Si, Y.; Williams, R.; et al. Validation of a Novel Murine Wound Model of Acinetobacter baumannii Infection. Antimicrob. Agents Chemother. 2013, 58, 1332-1342. [CrossRef]

33. Rampioni, G.; Pillai, C.R.; Longo, F.; Bondi, R.; Baldelli, V.; Messina, M.; Imperi, F.; Visca, P.; Leoni, L. Effect of efflux pump inhibition on Pseudomonas aeruginosa transcriptome and virulence. Sci. Rep. 2017, 7, 1-14. [CrossRef] [PubMed]

34. Stover, C.K.; Pham, X.Q.; Erwin, A.L.; Mizoguchi, S.D.; Warrener, P.; Hickey, M.J.; Brinkman, F.S.L.; Hufnagle, W.O.; Kowalik, D.J.; Lagrou, M.; et al. Complete genome sequence of Pseudomonas aeruginosa PAO1, an opportunistic pathogen. Nature 2000, 406, 959-964. [CrossRef]

35. Choi, K.-H.; Schweizer, H.P. mini-Tn7 insertion in bacteria with single attTn7 sites: Example Pseudomonas aeruginosa. Nat. Protoc. 2006, 1, 153-161. [CrossRef]

36. Farlow, J.; Freyberger, H.R.; He, Y.; Ward, A.M.; Rutvisuttinunt, W.; Li, T.; Campbell, R.; Jacobs, A.C.; Nikolich, M.P.; Filippov, A.A. Complete Genome Sequences of 10 Phages Lytic against Multidrug-Resistant Pseudomonas aeruginosa. Microbiol. Resour. Announc. 2020, 9. [CrossRef]

37. CLSI. Methods for Dilution Antimicrobial Susceptibility Tests for Bacteria that Grow Aerobically, 11th ed.; CLSI: Wayne, PA, USA, 2018.

38. Vipra, A.; Desai, S.N.; Junjappa, R.P.; Roy, P.; Poonacha, N.; Ravinder, P.; Sriram, B.; Padmanabhan, S. Determining the Minimum Inhibitory Concentration of Bacteriophages: Potential Advantages. Adv. Microbiol. 2013, 3, 181-190. [CrossRef]

39. Sopirala, M.M.; Mangino, J.E.; Gebreyes, W.A.; Biller, B.; Bannerman, T.; Balada-Llasat, J.-M.; Pancholi, P. Synergy Testing by Etest, Microdilution Checkerboard, and Time-Kill Methods for Pan-Drug-Resistant Acinetobacter baumannii. Antimicrob. Agents Chemother. 2010, 54, 4678-4683. [CrossRef]

40. Agún, S.; Fernández, L.; González-Menéndez, E.; Martínez, B.; Rodríguez, A.; García, P. Study of the Interactions between Bacteriophage phiIPLA-RODI and Four Chemical Disinfectants for the Elimination of Staphylococcus aureus Contamination. Viruses 2018, 10, 103. [CrossRef]

41. Regeimbal, J.M.; Jacobs, A.C.; Corey, B.W.; Henry, M.S.; Thompson, M.G.; Pavlicek, R.L.; Quinones, J.; Hannah, R.M.; Ghebremedhin, M.; Crane, N.J.; et al. Personalized Therapeutic Cocktail of Wild Environmental Phages Rescues Mice from Acinetobacter baumannii Wound Infections. Antimicrob. Agents Chemother. 2016, 60, 5806-5816. [CrossRef] [PubMed]

42. National Research Council. Guide for the Care and Use of Laboratory Animals, 8th ed.; National Academies Press: Washington, DC, USA, 2011.

43. Peleg, A.Y.; Jara, S.; Monga, D.; Eliopoulos, G.M.; Moellering, R.C.; Mylonakis, E. Galleria mellonella as a Model System to Study Acinetobacter baumannii Pathogenesis and Therapeutics. Antimicrob. Agents Chemother. 2009, 53, 2605-2609. [CrossRef]

44. Wood, D.E.; Lu, J.; Langmead, B. Improved metagenomic analysis with Kraken 2. Genome Biol. 2019, 20, 1-13. [CrossRef] [PubMed]

45. Bushnell, B. (v. 38. 63). BBDuk. Jt Genome Inst. Available online: https://jgi.doe.gov/data-and-tools/bbtools/bb-tools-userguide/bbduk-guide/ (accessed on 25 June 2020).

46. Miller, J.R.; Koren, S.; Sutton, G. Assembly algorithms for next-generation sequencing data. Genomics 2010, 95, 315-327. [CrossRef] [PubMed]

47. Hunt, M.; Mather, A.E.; Sánchez-Busó, L.; Page, A.J.; Parkhill, J.; Keane, J.A.; Harris, S.R. ARIBA: Rapid antimicrobial resistance genotyping directly from sequencing reads. Microb. Genom. 2017, 3, e000131. [CrossRef]

48. Feldgarden, M.; Brover, V.; Haft, D.H.; Prasad, A.B.; Slotta, D.J.; Tolstoy, I.; Tyson, G.H.; Zhao, S.; Hsu, C.-H.; McDermott, P.F.; et al. Validating the AMRFinder Tool and Resistance Gene Database by Using Antimicrobial Resistance Genotype-Phenotype Correlations in a Collection of Isolates. Antimicrob. Agents Chemother. 2019, 63. [CrossRef] [PubMed]

49. Nbsp; MLST. Available online: https://github.com/tseemann/mlst (accessed on 25 June 2020).

50. Jolley, K.A.; Bray, J.E.; Maiden, M.C.J. Open-access bacterial population genomics: BIGSdb software, the PubMLST.org website and their applications. Wellcome Open Res. 2018, 3, 124. [CrossRef] [PubMed]

51. Snippy. Rapid Haploid Variant Calling and Core Genome Alignment. Available online: https://github.com/tseemann/snippy (accessed on 25 June 2020).

52. Walker, B.J.; Abeel, T.; Shea, T.; Priest, M.; Abouelliel, A.; Sakthikumar, S.; Cuomo, C.A.; Zeng, Q.; Wortman, J.; Young, S.K.; et al. Pilon: An Integrated Tool for Comprehensive Microbial Variant Detection and Genome Assembly Improvement. PLoS ONE 2014, 9, e112963. [CrossRef]

53. Seemann, T. Prokka: Rapid Prokaryotic Genome Annotation. Bioinformatics 2014, 30, 2068-2069. [CrossRef] 